\title{
A STUDY OF CORRELATION OF PREOPERATIVE FINE NEEDLE ASPIRATION CYTOLOGY (FNAC) WITH HISTOPATHOLOGICAL EXAMINATION (HPE) IN GOITRE
}

\author{
Srirangaprasad K1, Nagaraj T. M², Madav D³, Ritesh Mahajan', Praveen Kumar ${ }^{5}$, George K. George ${ }^{6}$, Moby Boban ${ }^{7}$ \\ 1 Professor, Department of ENT, Rajarajeshwari Medical College and Hospital, Mysore Road, Bangalore. \\ 2 Professor, Department of ENT, Rajarajeshwari Medical College and Hospital, Mysore Road, Bangalore. \\ ${ }^{3}$ ENT Consultant, Department of ENT, Rajarajeshwari Medical College and Hospital, Mysore Road, Bangalore. \\ ${ }^{4}$ Senior Resident, Department of ENT, Rajarajeshwari Medical College and Hospital, Mysore Road, Bangalore. \\ ${ }^{5}$ Associate Professor, Department of ENT, Rajarajeshwari Medical College and Hospital, Mysore Road, Bangalore. \\ ${ }^{6}$ Post Graduate, Department of ENT, Rajarajeshwari Medical College and Hospital, Mysore Road, Bangalore. \\ ${ }^{7}$ Post Graduate, Department of ENT, Rajarajeshwari Medical College and Hospital, Mysore Road, Bangalore.
}

\begin{abstract}
BACKGROUND: FNAC is a simple, cost effective, readily repeated and quick to perform procedure, with excellent patient compliance. It is, however, not without limitations related to specimen adequacy, sampling techniques, and overlapping cytological features between benign and malignant follicular neoplasm. Here arises the need for Histopathological examination (HPE), as it is considered the final diagnostic test.

OBJECTIVE: This study aims at correlating the cytological diagnosis with the final histopathological diagnosis to evaluate the sensitivity, specificity and positive predictive value of smears and thereby its role in the preoperative diagnosis of thyroid swellings. METHODS: Data for the study was collected from patients undergoing thyroidectomy in Department of ENT, Head and Neck Surgery at Raja Rajeswari Medical College and Hospital, Bangalore. The study period was from $1^{\text {st }}$ October 2013 -30 needle aspiration cytology of the swelling was done on OPD basis for all patients presenting with goitre. Thyroidectomy specimens preserved in $10 \%$ formalin was sent for histopathology examination.

RESULTS: A total of 157 patients was evaluated, out of which 118 patients underwent FNAC. 15 were unsatisfactory aspirates. A total of 57 cases were operated specimens were available for histopathologic examination. The mean age of patients were 36.9 years. The ratio between female to males was $7.1: 1$. The sensitivity of FNAC was $87.5 \%$, the Specificity was $100 \%$, accuracy was $98.2 \%$, and the positive predictive value of a positive test for malignancy was $100 \%$.

CONCLUSION: FNAC of thyroid lesions has been shown to be safe, simple, cost effective and accurate method for management of palpable thyroid lesions. It not only facilitates the communication among cytopathologists, surgeons, radiologists, and endocrinologists but also facilitate research into the epidemiology, molecular biology, pathology and diagnosis of thyroid diseases.
\end{abstract}

KEYWORDS: Goitre, Fine Needle Aspiration Cytology, Histopathology.

HOW TO CITE THIS ARTICLE: Srirangaprasad K, Nagaraj T. M, Madav D, Ritesh Mahajan, Praveen Kumar, George K. George, Moby Boban. "A Study of Correlation of Preoperative Fine Needle Aspiration Cytology (FNAC) with Histopathological Examination (HPE) in Goitre". Journal of Evolution of Medical and Dental Sciences 2015; Vol. 4, Issue 89, November 05; Page: 15414-15417, DOI: $10.14260 /$ jemds/2015/2198.

INTRODUCTION: Thyroid is the largest endocrine gland in the body and the first to develop in fetal life. ${ }^{1}$ Any enlargement of the thyroid gland is called GOITRE, It may be diffuse, uninodular or multinodular. Most of them are benign and fewer than $5 \%$ are actually malignant. ${ }^{2}$ Fine Needle Aspiration Cytology (FNAC) as a method was first published by Leyden in 1883.3 FNAC, however, is not without limitations related to specimen adequacy, sampling techniques, skill of performing the aspiration, interpretation of the aspirate and overlapping cytological features between benign and malignant follicular neoplasm. Here arises the need for Histopathological examination (HPE), as it is considered the final diagnostic test. Thus even if nonsurgical and non-invasive techniques can provide a diagnosis, the ultimate answer rests in the histopathologic examination of the excised thyroid tissue.

Financial or Other, Competing Interest: None.

Submission 15-10-2015, Peer Review 16-10-2015,

Acceptance 24-10-2015, Published 04-11-2015.

Corresponding Author:

Dr. Srirangaprasad $K$,

C/o. House No. 424, $7^{\text {th }}$ Cross,

$1^{\text {st }}$ Block, Jayanagar, Bangalore-560011.

E-mail: ranganitha@yahoo.co.in

DOI:10.14260/jemds/2015/2198.
This also raises the question of how much corroborative is FNAC and HPE. ${ }^{4}$

This study is carried out with the objective of comparing the findings of the two tests namely FNAC and HPE in goitres and to make suggestions for the future.

MATERIALS AND METHODS; A total of 157 patients was evaluated with complaints related to thyroid pathologies. The study period was from $1^{\text {st }}$ October $2013-30^{\text {th }}$ September 2014. Patients with goitre and normal thyroid hormone profile undergoing thyroidectomy were included in the study. All patients with co-morbidities and unfit for surgery and those who refused for surgery were excluded from the study. An informed written consent was taken from the patients and ethical committee approval was taken from the institution.

Fine needle aspiration cytology of the swelling was done on OPD basis for all consenting patients presenting with goitre.

The 1.5 inch $23 \mathrm{G}$ disposable needle attached to a $10 \mathrm{ml}$ disposable syringe was used and inserted into the nodule in a direction perpendicular to the anterior surface of neck. The smeared specimen should be fixed immediately as air-drying causes loss of the nuclear detail, the preferred stain used was Hematoxylin and Eosin.Thyroidectomy specimens were collected in $10 \%$ formalin in fresh state and allowed to fix for 24 hours. 
The most commonly used fixative is $95 \%$ ethyl alcohol, either by immersion of the smears or as a spray fixative. Paraffin embedded H\&E stained sections were obtained and studied under light microscopy. The sensitivity and specificity of HPE Diagnosis and FNAC diagnosis were determined. In addition to sensitivity and specificity, the positive and negative predictive values and accuracy were calculated.

RESULTS: Out of total 157 patients, 118 underwent FNAC. 15 were unsatisfactory aspirates consisting of blood or inadequate aspirate. 57 cases were operated and specimen was available for histopathologic examination. Majority of the patients were in the age group of 21-40 years with mean age of 36.9 years. The ratio between females to males was 7.1: $1.94 .7 \%$ of the patients presented with complains of swelling in front of the neck, $3.5 \%$ of the patients complained of weight gain and dysphagia each and $1.8 \%$ of the patients complained of dyspnea and $1.8 \%$ complained of change in voice.

The patients presented with the above symptoms of duration ranging from 5 months to 10 years (120 months) with a median duration of 8 months. $54.4 \%$ and $26.3 \%$ of patients underwent hemi thyroidectomy and subtotal thyroidectomies respectively. $1.8 \%$ patients underwent hemi thyroidectomy with isthmusectomy, $8.8 \%$ patients underwent near total thyroidectomy and total thyroidectomies each. Neck dissection with central compartment clearance was done in two cases.

The accuracy of FNAC in the diagnosis of goitre cytologically was evaluated by using the predictive value theory. 'True-negative' (TN) and 'True-positive' (TP) cases are those, which are diagnosed correctly as benign and malignant respectively. 'False-positive' (FP) cases consist of those cases, which are benign but wrongly diagnosed as malignant. 'False-negative' (FN) refers to those cases, which are malignant but are diagnosed as benign. Based on study findings, the sensitivity, specificity, predictive value of positive test and accuracy for malignancy were determined. True Negative: 49; True Positive: 7; False Negative: 1; False Positive: 0

DISCUSSION: Fine needle aspiration cytology (FNAC) has an essential role in the evaluation of patients with goitre. The present study was undertaken to evaluate preoperatively with the help of FNAC, the type of thyroid lesion and to correlate the observations with the histopathological examination in order to determine the usefulness of the technique. In the present study 23 gauge and one and half inch long disposable needle was used. Friedman et al. (1979). ${ }^{5}$ and Braun and Silver (1984). ${ }^{6}$ used 18 and 19 gauge needles respectively for cystic lesions.

The length of the needle favoured was one and half inches and in the present study the same was found to be of optimum length as it reached all the areas in a thyroid nodule and are least traumatic, less painful and perfectly sterile.

In our series a $10 \mathrm{ml}$ disposable syringe was used with special syringe holder. Special syringe holder helps to apply suction and release with one hand only while the other hand fixes the swelling. Walfish et al (1977) used $10 \mathrm{ml}$ syringe fitted with an 18-gauge needle for cystic lesions. ${ }^{7}$

A local anaesthetic was infiltrated into the skin to avoid pain to the patient by Colacchio TA et al. (1980). ${ }^{8}$ and Norton W et al. (1982). ${ }^{9}$ None of the patients complained of significant pain in the present study. There is no need of local anaesthesia we feel, when a fine and disposable needle (22-24G) is used.

Majority (103) of the aspirates done by routine FNAC were satisfactory for cytological evaluation with satisfactory smear rate of $87.3 \%$. Among the remaining inconclusive aspirates, USG guided FNAC was done which yielded sufficient material for the cytological study in most of them. The rate in our present study $(87.3 \%)$ was better than those in studies by Tabaqchali et al. and Kamal et al. (70.02\%- 72.4\%). ${ }^{10,11}$ and was comparable to study by Silverman et al $(88.34 \%) .{ }^{12}$

Age Distribution: The mean age of the patients subjected to surgery was 39.6 years. The age of the patients of Klemi PJ et al. ${ }^{13}$ ranged from 21 to 86 years with the mean age of 50 years. In the present series, patients in the $4^{\text {th }}$ and $5^{\text {th }}$ decades of life comprised $68.4 \%$. In the same age group, Pandit AA and Kinare. ${ }^{14}$ have reported $62 \%$.

Sex Incidence: The sex ratio (female: male) in the present study group was 7.1:1 with 50 women and 7 men. In the series of Gershengom et al female to male ratio was 28:5, Harsoulis et al series it was 993:107 (9:1) and the male proportion in the Colacchio et al series was $16 \%$.

Accuracy Rate: The overall accuracy was more than $75 \%$ in the some series on the subject reported by various authors and more than $90 \%$ in other series. In our study the accuracy was $98.2 \%$.

False Negative: The false negatives ranged from $0 \%$ to $23 \%$ in various series. But majority of the false negatives were below $7 \%$ and in the present study it was $1.8 \%$. The possibility of papillary carcinoma with cystic degeneration must be kept in mind in cystic lesions though most of them are benign..$^{15}$ and wall must be aspirated after evacuating the cyst completely. ${ }^{16}$

False Positive: In our study, the false positive was just one percent. The high rate of $23.5 \%$ of false positives in the series of Ramaciotti et al (1984) was due to inclusion of smears suggestive of malignancy in the malignant category. Suen KC, Quenville NF (1983).17 concluded the common false positives as (a) Cellular colloid goitre mistaken for neoplasm, (a) Thyroiditis mistaken for lymphoma and (c) Cellular atypia due to hyperplastic reaction in adenoma.

Predictive Value: The predictive values of FNAC with reference to malignancy in the present series are: Sensitivity- $87.5 \%$; Specificity- 100\%; Overall accuracy: $98.2 \%$; Predictive value of a positive result: $100 \%$

Sensitivity And Specificity: According to Frable MA (1980) for an acceptable screening test FNAC should have sensitivity and specificity of more than $83 \%$. In a large cyst over $4 \mathrm{cms}$ that reaccumulates haemorrhagic fluid after complete evacuation, according to Suen KC and Quenville NF (1983). ${ }^{17}$ malignancy should be suspected. The accuracy has not exceeded $90 \%$ with Vim-Silvermann needle in the works of Crile and Vickery (65\%), Hamlin and Vickery (74\%), Ferrita and Verace (67\%), Singh Prithipal et al. ${ }^{16}$ (72\%) and Wang Chu et al (90\%). 
The procedure is painful and traumatic and the specimen obtained is less representative. FNAC has been favoured as the first choice for the examination of a solitary nodule of thyroid. FNAC can also recognize the underlying thyroiditis in hypothyroidism or hyperthyroidism (Tanu EM et al., 1988; Klemi PJ et al., 1990; Godinho L et al., 1992).

Since the regular use of FNAC, unnecessary operations on thyroid have decreased, cancer yield has increased and medical expenses and bed occupancy have reduced (Hamberger B et al., 1982). ${ }^{18}$ Sclabas GM et al. ${ }^{19}$ conducted a study for 240 patients. FNAC results were $32 \%$ positive for malignancy, $22 \%$ negative for malignancy, $42 \%$ were indeterminate for malignancy and 5\% were non-diagnostic. In most of the studies, mistakes were because of:

(a) Confusion between nodular colloid or hyperplastic nodular goitre and Hashimoto's thyroiditis, especially with Hurthle cell neoplasms. Orrel R. ${ }^{20}$ has quoted it as one of the difficulties in interpretation in $4-6 \%$ of the cases.

(b) Difficulty in distinguishing between multinodular goitre from follicular neoplasm.

(c) Also presence of multiple pathologies in the same gland may result in geographic misses and lead to improper diagnosis.

It reiterates the fact that a negative FNAC report should not modify the clinical diagnosis and proposed line of management, but a decision can definitely be made viewing in conjunction with the clinical picture and the biochemical parameters.

CONCLUSION: Fine needle aspiration cytology has essential role in the evaluation of euthyroid patients with goiter. It not only facilitates the communication among cytopathologists, surgeons, radiologists, and endocrinologists but also facilitate research into the epidemiology, molecular biology, pathology and diagnosis of thyroid diseases. USG guided FNAC should be done whenever necessary thereby eliminating the false negative cases.

Low rate of false positive and false negative case can be achieved by applying strict criteria for specimen adequacy. FNAC is a valuable investigation in identifying occult neoplasms.

We wish to stress the importance of doing multiple aspirations at different sites and usage of USG guidance for representative areas of suspected pathology, because of the fact that thyroid is affected by many lesions at a time. The diagnostic accuracy can be improved when combined with advanced imaging techniques, immunologic analysis and electron microscopy and there-by the management of thyroid diseases.

\section{BIBLIOGRAPHY:}

1. Chandanwale Shirish, Singh Neha, Kumar H, Pradhan P, Gore C, Rajpal M. Clinicopathological correlation of thyroid nodules. Int J Pharm Biomed Sci 2012,3(3),97102.

2. Lal Geetha, Clark.H.Orlo, Schwartz's Principles of Surgery, Ninth ed. McGraw Hill publications, pg 13431369.
3. Martin HE, Ellis EB. Biopsy by needle puncture and aspiration. Ann Surg. 1930; 92: 169-181.

4. Das Dipanwita, Sarma MC, Sharma A, Datta TK, SK Lahiri, A Comparative study between fine needle aspiration cytology and histopathological examination in the diagnosis of neoplastic and non-neoplastic lesions of the thyroid gland. Indian J. Prev.Soc.Med.vol.43 no.1, 2012.

5. Friedman M, Shimaoka K, Rao U. Diagnosis of chronic lymphocytic thyroitis (nodular presentation) by needle aspiration. Acta Cytol 1981; 25: 513-22.

6. Braun RJ, Silver CE. Needle aspiration biopsy of the thyroid nodules. Laryngoscope 1984; 94: 38-42.

7. Walfish PG, Hazani E, Strawbridge HT. Combined ultrasound and needle aspiration cytology in the assessment and management of hypofunctioning thyroid nodule. Ann Intern Med 1976;143: 365-8.

8. Collachio TA, Gerfo P, Feind CR. Fine needle aspiration diagnosis of thyroid nodules. Review and report of 300 cases. The Am J Surg 1980; 140: 568-71.

9. Norton LW, Wangensteen SL, Davis JR, Paplamos SH, Werner SC. Utility of thyroid aspiration biopsy. Surgery 1982; 92:700-5.

10. Tabaqchali MA, Hanson JM, Johnson SJ, Wadehra V, Proud G. Thyroid aspiration of cytology in New Castle; a six year cytology histology correlation study. Annals R Coll Surgery England 2000;82(3):149-55.

11. Kamal M, Dilip G A,Hemant R K Comparative study of fine needle aspiration and fine needle capillary sampling of thyroids lesions. Acta Cytol 2002, Jan / Feb: 46 (1): $p$ p 30-34.

12. Silverman JF et al. The role of fine needle aspiration biopsy in the rapid diagnosis and management of thyroid neoplasm. Cancer 1986; 57 : pp 1164- 1170.

13. Klemi PJ, Joensuu H, Nylama E. Fine needle aspiration biopsy in the diagnosis of thyroid nodules. Acta Cytol 1991;35(4):434-8.

14. Pandit AA, Kinare SG. Fine needle aspiration cytology of the thyroid. Indian Journal of Medicine 1986;23:54-8.

15. Wang C, Vickery AL, Maluf F. Needle biopsy of the thyroid. Surgery, Gynecol, Obstet 1976;143:365-8.

16. Chu FW, Hanson TA, Goldman JM, Robbins J. Study of cells in fine needle aspirations of the thyroid gland. Acta Cytol 1979;23:309-14.

17. Suen KC, Quenville NF. Fine needle aspiration biopsy of thyroid gland: a study of 304 cases. J Clin Pathol 1983;36:1036-45.

18. Hamburger B, Gharib H, Melton LJ III. Fine needle aspiration biopsy of the thyroid nodules: Impact on thyroid practice and cost of care. Am J Med 1982; 73: 381-4.

19. Sclabas GM, Staerkel GA, Shapiro SE, Fornage BD, Sherman SF.Fine needle aspiration of thyroid and correlation with histopathology in a contemporary series of 240 patients. Am Journal of Surgery 2003;186(6):702-9.

20. Orrel R. Thyroid. 3rd ed. In: Manual and atlas of fine needle aspiration cytology, Street FG, Max N (eds). London: Churchill Livingstone; 1999. p.109-39. 


\begin{tabular}{|c|c|c|c|}
\hline \multirow{2}{*}{ Cytology } & \multicolumn{2}{|c|}{ Histology } & \multirow{2}{*}{$\begin{array}{c}\text { Total } \\
\text { Cytology }\end{array}$} \\
\cline { 2 - 3 } & Benign & Malignant & \\
\hline $\begin{array}{c}\text { Benign } \\
\text { (No malignant cells) }\end{array}$ & 49 & 1 & 50 \\
\hline $\begin{array}{c}\text { Malignant } \\
\text { (Malignant cells) }\end{array}$ & 0 & 7 & 7 \\
\hline Total Histology & 49 & 8 & 57 \\
\hline \multicolumn{2}{|c|}{ Table 1: Predictive value of FNAC in goiter } \\
\hline
\end{tabular}

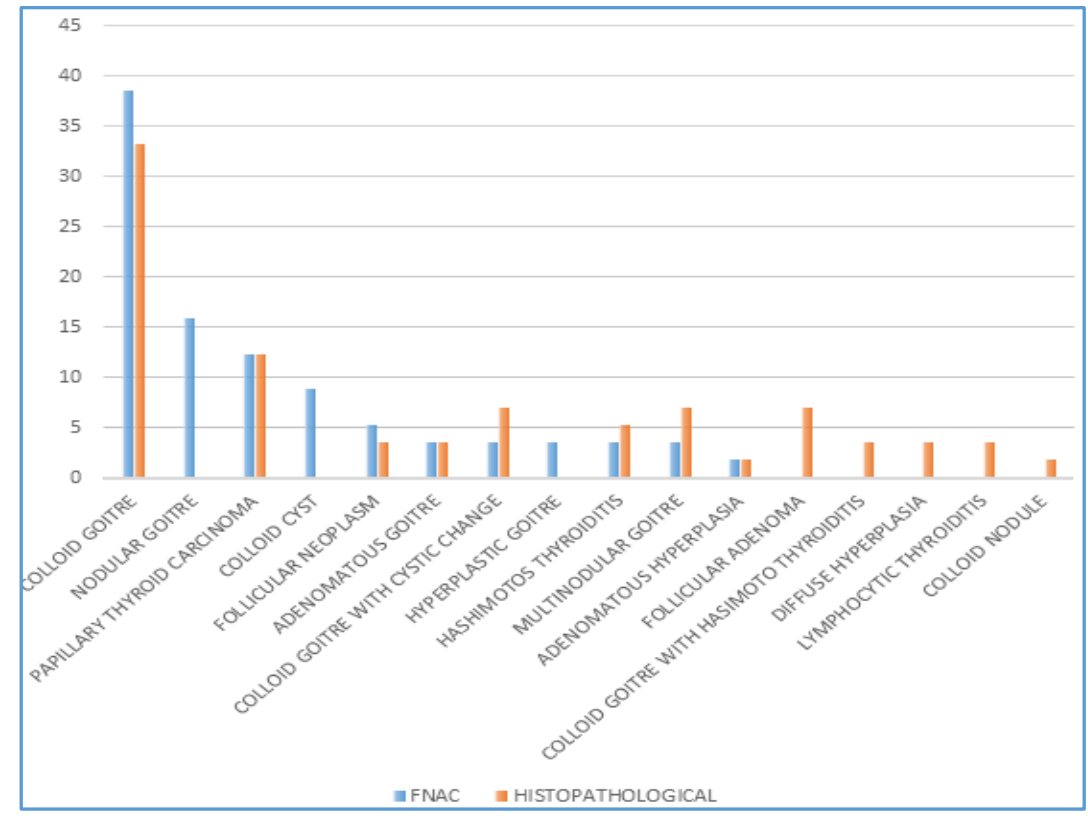

Fig.1: FNAC and Histopathological diagnosis analysis

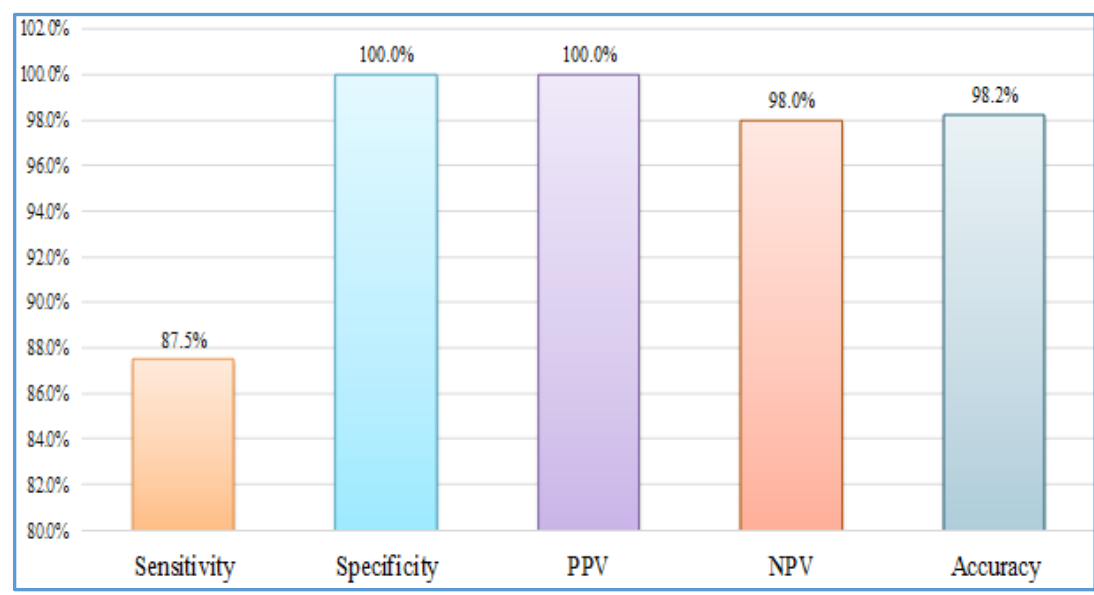

Fig. 2: Sensitivity, Specificity, PPV, NPV and Accuracy of HPE Diagnosis and FNAC Diagnosis 